UDC 53.072; 53:681.3

\author{
${ }^{* 1}$ Shmygaleva T.A., ${ }^{2}$ Shmygalev E.V., ${ }^{2}$ Kupchishin A.I., \\ ${ }^{1}$ Jeleunova Sh.E., ${ }^{1}$ Cherikbayeva L.Sh. \\ ${ }^{1}$ Faculty of Mechanics and Mathematics, al-Farabi Kazakh National University, Almaty, Kazakhstan \\ ${ }^{2}$ Abai Kazakh National Pedagogical University, Almaty, Kazakhstan \\ *e-mail: shmyg1953@mail.ru
}

\title{
Mathematical modeling of radiation processes in constructional materials in ion irradiation
}

\begin{abstract}
Processes of radiation formation of defects in the iron exposed to radiation by various ions are considered in the work. Issues of application of iron and alloys on the basis of iron in the industry are searched. The algorithm is developed for calculation of cascadely - probabilistic functions (CPF), concentration of radiation defects, computations are led, the regularities arising at calculations of cascadely - probabilistic functions depending on initial energy of a primary particle, atomic number of a flying particle, depth of penetration. Also calculations of concentration of radiating defects are executed at an ionic irradiation in iron. Areas of finding of result for CPF, calculated depending on number of interactions and depth of penetration, concentration of cascade areas are received. It is matched approximated expression and coefficients of approximation for various flying particles in iron are found. Results of calculations are presented in the form of tables and schedules.

Key words: structural material, alloy steel, cascadely - probabilistic function, steel, cast iron, iron, ion, approximation, concentration, irradiation defects, energy.
\end{abstract}

\section{Introduction}

The technique, which allows receiving analytical expressions and count cascading activities throughout the depth of the irradiated material to harden the material and metal compounds, mainly in the surface layer is suggested in this work.

Structural materials cover a multitude of different materials used in the manufacture for producing the parts of constructions, machinery and technical products. The ability to create any structure and its efficiency depends on the availability of materials with suitable mechanical properties. For example, for the manufacture of a modern car alloyed steel is needed, metal aircraft became a reality only also with the advent of technology and durable aluminium alloys. Modern high-rise buildings would look differently if it were not glass materials. White cast iron is a stronger form of gray one with the content of $2.5 \%$ carbon, less than $1 \%$ of silicon and less than $1 \%$ manganese. Carbon is part of cast iron in the form of carbides (cementite). White cast iron is very strong, but as gray one low-plastic. It is primarily used as a wearresistant material, e.g. for balls and armored plates of grinding mill, milling minerals. White cast iron can be heat-treated to transform into a so-called ductile iron. Ductile iron is much more flexible than the gray and white, but less durable and is not as solid. Ductile cast irons are used mainly for complex castings, such as pipe armature, chains, and fasteners for scaffoldings. High strength cast iron produced from grey by modifying their crystalline structure for retrieving spherical graphite. Cast iron with spheroidal graphite is widely used in the automotive industry (cranked axles and camshafts, brackets, hubs, slides of brake systems, main transmission gears, etc.), metallurgy (ingot moulds), heavy engineering industry (turbines, mill rolls), transport and agricultural machinery. The most common type of steel used in construction of buildings and bridges, is a structural steel containing $0.1-0.25 \%$ carbon and alloying elements such as manganese and silicon, in quantities of less than $1 \%$. Another group of steels is heat resistant (oxidationresistant) alloys. They have a high content of chromium, molybdenum or nickel and applied in vaporous boilers, gas-turbine installations, aircraft engines, furnaces and oven conveyors-everywhere, where the temperature may be $400-1400^{\circ} \mathrm{C}$. Special steels include tool steels. They contain a lot of carbon $(0.8-2.0 \%)$ and quite a lot of alloying 
elements for education not only solid martensite, but also solid carbides. Typical alloying elements of such steel as chromium, molybdenum, tungsten and vanadium. Tool steels are usually heat-treated on high strength. Some of instrumental steels - fastcutting are able to retain their hardness in cutting instruments to temperatures reaching $600{ }^{\circ} \mathrm{C}$. The content of alloying elements in instrumental steels are usually higher than in any other alloy steels.

\section{Main body}

As an example, figures 1-4 present the distribution of implanted ions of iron and carbon and energy loss on depth in irradiated iron depending on depth to the different energies of incident ions: 1-245; 2-350; 3-500 keV. Curves of distribution of implanted ions to different energies for both carbon and iron have well-pronounced highs and their concentration is unevenly distributed over the depth of the iron. Calculations show the distribution of energy losses on ionization and excitation on the depth of the material is quite sharply decreasing function. Distribution of knocked-on atoms on depth repeated distribution of impurity concentration in some extent. Comparing calculations of distributions of implanted carbon particle $(245 \mathrm{keV})$ and iron $(350 \mathrm{keV})$ in the iron, see their quite good acceptance. Little difference calculations with experimental data for carbon associated with incomplete account of influence of environment temperature.

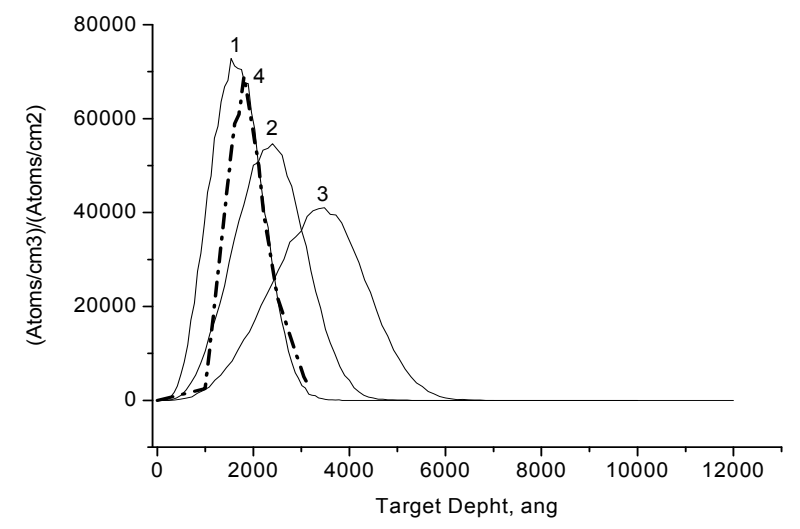

$1-245 ; 2-350 ; 3-500 \mathrm{keV} ; 4-$ experiment $(245 \mathrm{keV})$

Figure 1 - Distribution of implanted carbon on the iron depth during bombardment his streams of ions of different energies

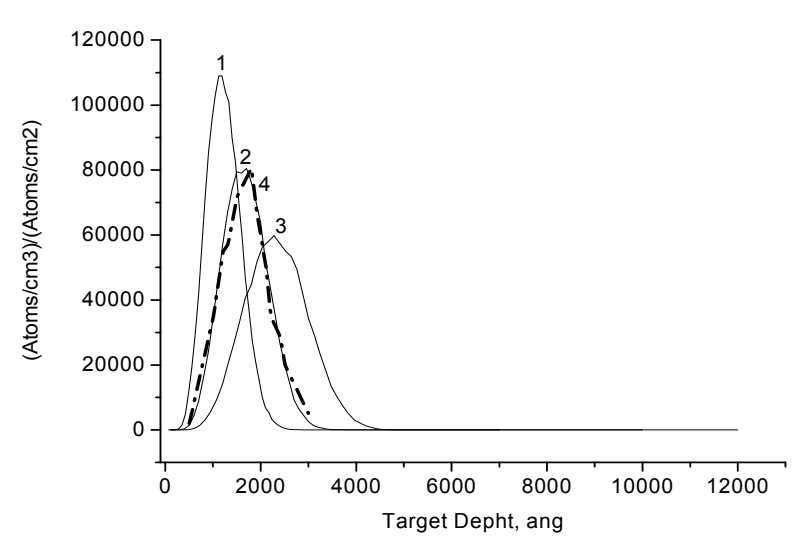

Figure 2 - Distribution of implanted iron on depth of iron during bombardment his particle flows different energies

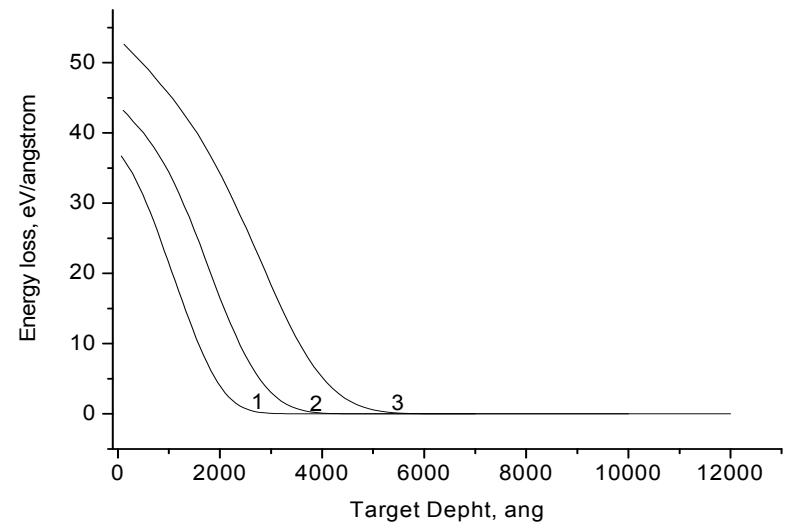

$1-245 ; 2-350 ; 3-500 \mathrm{keV}$

Figure 3 - The distribution of energy losses through the depths of the iron under carbon ions irradiation of different energies

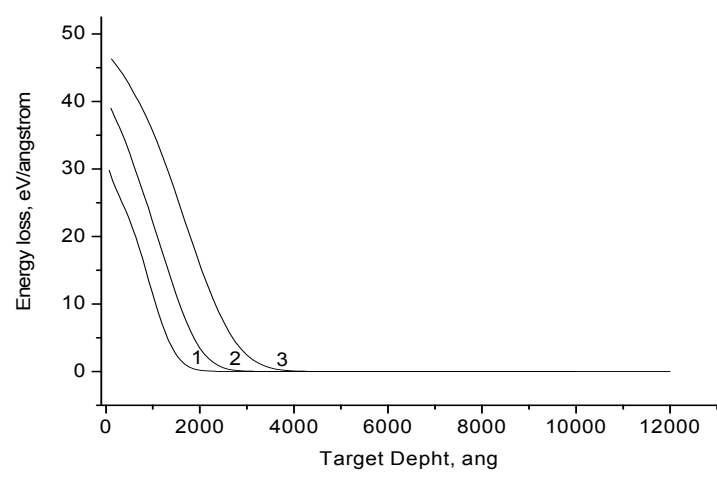

$1-245 \mathrm{keV} ; 2-350 \mathrm{keV} ; 3-500 \mathrm{keV}$

Figure 4 - The distribution of energy losses in depth during irradiation of iron by iron ions of different energies 


\section{Conclusion}

Alloys on the basis of iron (steel, cast iron) are considered in the work, as now beams of ions are intensively applied in mechanical engineering at deriving of ultrastrong details and materials. The cascadely - probabilistic method (CPM) is used for this purpose, in which basis is recipience of analytical expressions and further use of cascadely probabilistic functions (CPF). CPF mean probabilities that the particle generated on some depth h' will reach of depth $\mathrm{h}$ after $\mathrm{n}$ numbers impacts.

$\mathrm{CPF}$ expression for ions in view of losses of energy has a following appearance [1]:

$$
\psi_{n}\left(h^{\prime}, h, E_{0}\right)=\frac{1}{n ! \lambda_{0}{ }^{n}}\left(\frac{E_{0}-k h^{\prime}}{E_{0}-k h}\right)^{-l} \exp \left(\frac{h-h^{\prime}}{\lambda_{0}}\right) *\left[\frac{\ln \left(\frac{E_{0}-k h^{\prime}}{E_{0}-k h}\right)}{a k}-\left(h-h^{\prime}\right)\right]^{n} .
$$

For calculation of CPF the following modernized formula convenient for computation is received:

$$
\psi_{n}\left(h_{2} h_{i} E_{0}\right)=\prod_{i=1}^{n}\left[\left(\frac{\frac{\ln \left(\frac{E_{0}-k h^{i}}{E_{0}-k h}\right)}{a k}-\left(h-h^{i}\right)}{\lambda_{0} t}\right) * \exp \left(\frac{h-h^{5}}{\lambda_{0}}-\frac{1}{\lambda_{0} a k}\left(\frac{E_{0}-k k^{i}}{E_{0}-k h}\right)\right)\right]
$$

where $\mathrm{n}$ is the number of interactions, $\mathrm{h}$ ', $\mathrm{h}$ are depths of generation and registration of an ion accordingly, $\lambda_{0}, a, E_{0}, k$ are parameters of approximation.

To find parameters of approximation the following approximation expression were used [1]:

$$
\sigma(h)=\sigma_{0}\left(\frac{1}{a\left(E_{0}-k h\right)}-1\right)
$$

Dependences approximation curve $\sigma$ from $\mathrm{h}$ are resulted in figure 5. Further calculations of cascadely - probabilistic functions depending on number of interactions and depth of penetration of particles are led. Areas of a finding of result are found and the regularities of CPF behaviour from number of interactions and from depth of penetration of particles are revealed (tab. 1,2, fig. 6).

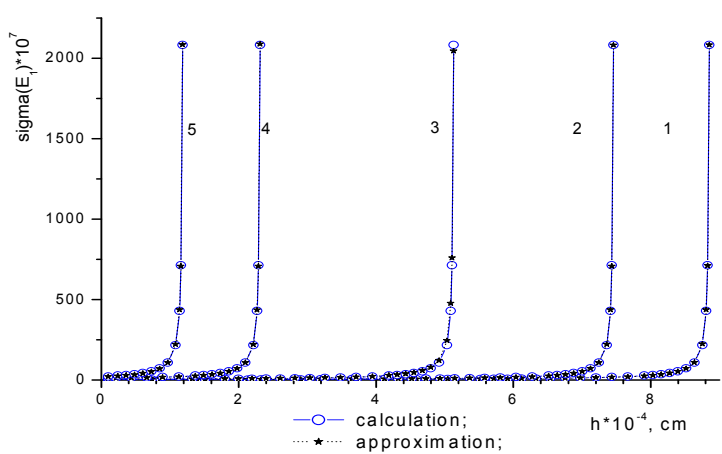

Figure 5 - Approximation of the modified section of cascadely - probabilistic function: for nitrogen in iron for $E_{0}=1000$ (1), 800 (2), 500 (3), 200 (4), $100(5) \mathrm{keV}$.

Coefficient of correlation $\eta=0,9999$

Table 1 - Dependence of displacement percent of the left and right borders of result area from number of interactions for silicon in iron for a) $E_{0}=1000 \mathrm{keV}$; b) $\mathrm{E}_{0}=800 \mathrm{keV}$; c) $\mathrm{E}_{0}=500 \mathrm{keV}$; d) $\mathrm{E}_{0}=200 \mathrm{keV}$; e) $\mathrm{E}_{0}=100 \mathrm{keV}$

\begin{tabular}{|c|c|c|c|c|}
\hline $\mathrm{h}^{*} 10^{4}, \mathrm{~cm}$ & $\mathrm{~B}_{1}, \%$ & $\mathrm{~B}_{2}, \%$ & $\mathrm{~N}_{\mathrm{n}}$ & $\mathrm{B}_{3}, \%$ \\
\hline 0,5 & 35 & 23 & 20 & 58 \\
\hline 1,2 & 34 & -3 & 35 & 31 \\
\hline 1,9 & 38 & -18 & 45 & 20 \\
\hline 2,6 & 44 & -31 & 55 & 13 \\
\hline 3,3 & 50,8 & -41 & 69 & 9,8 \\
\hline
\end{tabular}




\begin{tabular}{|c|c|c|c|c|}
\hline 4 & 58,3 & $-51,7$ & 82 & 6,6 \\
\hline 4,7 & 67,3 & $-63,2$ & 105 & 4,1 \\
\hline 5,4 & 79,1 & $-77,1$ & 130 & 2 \\
\hline
\end{tabular}

a)

\begin{tabular}{|c|c|c|c|c|}
\hline $\mathrm{h}^{*} 10^{4}, \mathrm{~cm}$ & $\mathrm{~B}_{1}, \%$ & $\mathrm{~B}_{2}, \%$ & $\mathrm{~N}_{\mathrm{n}}$ & $\mathrm{B}_{3}, \%$ \\
\hline 0,5 & 32 & 16 & 22 & 48 \\
\hline 1,1 & 32,5 & -6 & 55 & 26,5 \\
\hline 1,7 & 37,5 & $-19,5$ & 62 & 12,2 \\
\hline 2,3 & 44,2 & -32 & 70 & 8,1 \\
\hline 2,9 & 51,6 & $-43,5$ & 79 & 5,6 \\
\hline 3,5 & 60,2 & $-54,6$ & 100 & 3,3 \\
\hline 4,1 & 70,8 & $-67,5$ & 140 & 1,1 \\
\hline 4,7 & 86,15 & $-85,05$ & & \\
\hline
\end{tabular}

b)

\begin{tabular}{|c|c|c|c|c|}
\hline $\mathrm{h}^{*} 10^{4}, \mathrm{~cm}$ & $\mathrm{~B}_{1}, \%$ & $\mathrm{~B}_{2}, \%$ & $\mathrm{~N}_{\mathrm{n}}$ & 13 \\
\hline 0,1 & 42 & 47 & 33 & 89 \\
\hline 0,5 & 28 & 58 & 48 & 86 \\
\hline 0,9 & 32 & -11 & 60 & 21 \\
\hline 1,3 & 38 & -24 & 70 & 14 \\
\hline 1,7 & 45,5 & $-35,5$ & 85 & 7 \\
\hline 2,1 & 54 & -47 & 99 & 4,1 \\
\hline 2,5 & 64,3 & $-60,2$ & 125 & 1,95 \\
\hline 2,9 & 78,15 & $-76,2$ & & $\mathrm{~B}_{3}, 2$ \\
\hline
\end{tabular}

c)

\begin{tabular}{|c|c|c|c|c|}
\hline $\mathrm{h}^{*} 10^{4}, \mathrm{~cm}$ & $\mathrm{~B}_{1}, \%$ & $\mathrm{~B}_{2}, \%$ & $\mathrm{~N}_{\mathrm{n}}$ & $\mathrm{B}_{3}, \%$ \\
\hline 0,1 & 27 & 21 & 25 & 48 \\
\hline 0,3 & 26,5 & $-3,5$ & 46 & 23 \\
\hline 0,5 & 33,5 & -19 & 62 & 14,5 \\
\hline 0,7 & 43 & $-33,5$ & 91 & 9,5 \\
\hline 0,9 & 54,7 & -49 & 120 & 5,7 \\
\hline 1,1 & 70,5 & $-67,6$ & 2,9 \\
\hline
\end{tabular}

d)

\begin{tabular}{|c|c|c|c|c|}
\hline $\mathrm{h}^{*} 10^{4}, \mathrm{~cm}$ & $\mathrm{~B}_{1}, \%$ & $\mathrm{~B}_{2}, \%$ & $\mathrm{~N}_{\mathrm{n}}$ & 12 \\
\hline 0,1 & 48 & 60 & 32 & $\mathrm{~B}_{3}, \%$ \\
\hline 0,8 & 23,5 & 10 & 45 & 33,5 \\
\hline 1,5 & 25 & -4 & 60 & 21 \\
\hline 2,2 & 29,7 & $-14,5$ & 72 & 15,2 \\
\hline 2,9 & 36 & -25 & 80 & 11 \\
\hline 3,6 & 43,5 & $-35,4$ & 95 & 6,1 \\
\hline 4,3 & 52,5 & $-46,5$ & 110 & 6 \\
\hline 5 & 63,4 & $-59,6$ & 135 & 3,8 \\
\hline 5,7 & 78,05 & $-76,3$ & & 1,75 \\
\hline
\end{tabular}

e)

International Journal of Mathematics and Physics 6, №2, 49 (2015) 
Table 2 - Dependence of displacement percent of the left and right borders of result area from depth of penetration for silicon in iron for a) $E_{0}=1000 \mathrm{keV}$; b) $\mathrm{E}_{0}=800 \mathrm{keV}$; c) $\mathrm{E}_{0}=500 \mathrm{keV}$; d) $\mathrm{E}_{0}=200 \mathrm{keV}$

\begin{tabular}{|c|c|c|c|c|c|}
\hline$h^{*} 10^{4}, \mathrm{~cm}$ & $h / \lambda$ & $\mathrm{C}_{1}, \%$ & $\mathrm{C}_{2}, \%$ & $\mathrm{~N}_{\mathrm{h}}$ & $\mathrm{C}_{3}, \%$ \\
\hline 0,5 & 473 & 17,5 & 41,2 & 22 & 58,7 \\
\hline 1,2 & 1477 & $-4,2$ & 34 & 49 & 29,8 \\
\hline 1,9 & 3062 & -17 & 36,3 & 90 & 19,3 \\
\hline 2,6 & 5585 & $-25,5$ & 37,5 & 155 & 12 \\
\hline 3,3 & 9765 & $-30,3$ & 37 & 285 & 6,7 \\
\hline 4 & 17310 & $-30,65$ & 33,7 & 625 & 3,05 \\
\hline 4,7 & 33513 & $-24,65$ & 25,35 & 2550 & 0,7 \\
\hline
\end{tabular}

a)

\begin{tabular}{|c|c|c|c|c|c|}
\hline$h^{*} 10^{4}, \mathrm{~cm}$ & $h / \lambda$ & $\mathrm{C}_{1}, \%$ & $\mathrm{C}_{2}, \%$ & $\mathrm{~N}_{\mathrm{h}}$ & $\mathrm{C}_{3}, \%$ \\
\hline 0,5 & 670 & 13 & 35 & 25 & 48 \\
\hline 1,1 & 1899 & $-6,5$ & 33,7 & 62 & 27,2 \\
\hline 1,7 & 3832 & $-18,5$ & 34,7 & 112 & 16,2 \\
\hline 2,3 & 6943 & $-26,5$ & 36,5 & 200 & 10 \\
\hline 2,9 & 12255 & $-30,5$ & 36 & 355 & 5,5 \\
\hline 3,5 & 22464 & $-29,22$ & 31,3 & 915 & 2,08 \\
\hline 4,1 & 47689 & $-20,115$ & 20,36 & 6700 & 0,145 \\
\hline
\end{tabular}

b)

\begin{tabular}{|c|c|c|c|c|c|}
\hline$h^{*} 10^{4}, \mathrm{~cm}$ & $h / \lambda$ & $\mathrm{C}_{1}, \%$ & $\mathrm{C}_{2}, \%$ & $\mathrm{~N}_{\mathrm{h}}$ & $\mathrm{C}_{3}, \%$ \\
\hline 0,1 & 215 & 35 & 57 & 31 & 94 \\
\hline 0,5 & 1343 & 3,5 & 31 & 44 & 34,5 \\
\hline 0,9 & 3056 & -11 & 31,5 & 35 & 20,5 \\
\hline 1,3 & 5719 & $-21,3$ & 34 & 138 & 12,7 \\
\hline 1,7 & 10075 & -28 & 35,5 & 250 & 7,5 \\
\hline 2,1 & 17919 & $-30,1$ & 33,5 & 585 & 3,4 \\
\hline 2,5 & 34964 & $-24,95$ & 25,77 & 2250 & 0,82 \\
\hline
\end{tabular}

c)

\begin{tabular}{|c|c|c|c|c|c|}
\hline$h^{*} 10^{4}, \mathrm{~cm}$ & $h / \lambda$ & $\mathrm{C}_{1}, \%$ & $\mathrm{C}_{2}, \%$ & $\mathrm{~N}_{\mathrm{h}}$ & $\mathrm{C}_{3}, \%$ \\
\hline 0,1 & 715 & 16,5 & 30,5 & 25 & 47 \\
\hline 0,3 & 2714 & $-4,5$ & 28 & 62 & 23,5 \\
\hline 0,5 & 5949 & $-17,7$ & 31,5 & 126 & 13,8 \\
\hline 0,7 & 11664 & $-26,9$ & 34,2 & 242 & 7,3 \\
\hline 0,9 & 23618 & $-28,75$ & 31,2 & 712 & 2,45 \\
\hline 1,1 & 60923 & $-17,338$ & 17,45 & 15500 & 0,112 \\
\hline
\end{tabular}

d)

\begin{tabular}{|c|c|c|c|c|c|}
\hline$h^{*} 10^{4}, \mathrm{~cm}$ & $h / \lambda$ & $\mathrm{C}_{1}, \%$ & $\mathrm{C}_{2}, \%$ & $\mathrm{~N}_{\mathrm{h}}$ & $\mathrm{C}_{3}, \%$ \\
\hline 0,1 & 151 & 43 & 63 & 7 & 106 \\
\hline 0,8 & 1403 & 7,8 & 26 & 40 & 33,8 \\
\hline 1,5 & 3088 & $-4,5$ & 26 & 112 & 21,5 \\
\hline 2,2 & 5428 & -14 & 29 & 190 & 15 \\
\hline 2,9 & 8831 & $-21,9$ & 32 & 310 & 6 \\
\hline 3,6 & 14135 & $-27,4$ & 33,4 & 700 & 2,65 \\
\hline 4,3 & 23362 & $-28,65$ & 31,3 & 3550 & 0,538 \\
\hline 5 & 42992 & $-22,784$ & 23,322 & & \\
\hline
\end{tabular}

e) 

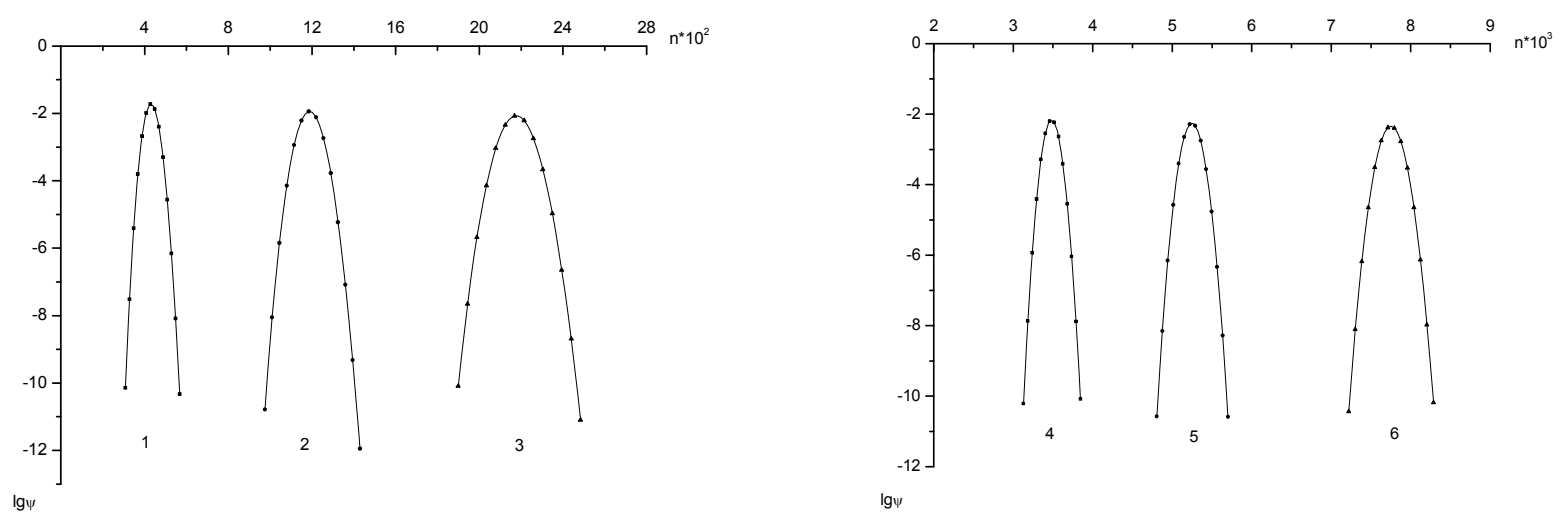

Figure 6 - CPF dependence for silicon in iron from number of interactions for $E_{0}=1000 \mathrm{keV}$ and $\mathrm{h}=0,5^{*} 10^{-4} ; 1,2 * 10^{-4} ; 1,9 * 10^{-4} ; 2,6^{*} 10^{-4} ; 3,3^{*} 10^{-4} ; 4,0^{*} 10^{-4}(\mathrm{~cm})(1-6)$.

Concentration of radiating defects at an ionic irradiation was calculated under the following formula [1].

$$
C_{k}\left(E_{0}, h\right)=\frac{E_{d}}{E_{c}} \frac{\left(E_{2 \max }-E_{c}\right)}{\left(E_{2 \max }-E_{d}\right)} \sum_{n=n_{0} h-k \lambda_{2}}^{n_{1}} \int_{n}^{h} \psi_{n}\left(h^{\prime}\right) \exp \left(-\frac{h-h^{\prime}}{\lambda_{2}}\right) \frac{d h^{\prime}}{\lambda_{1}\left(h^{\prime}\right) \lambda_{2}}
$$

Results of calculations are presented in figures 7,8 .

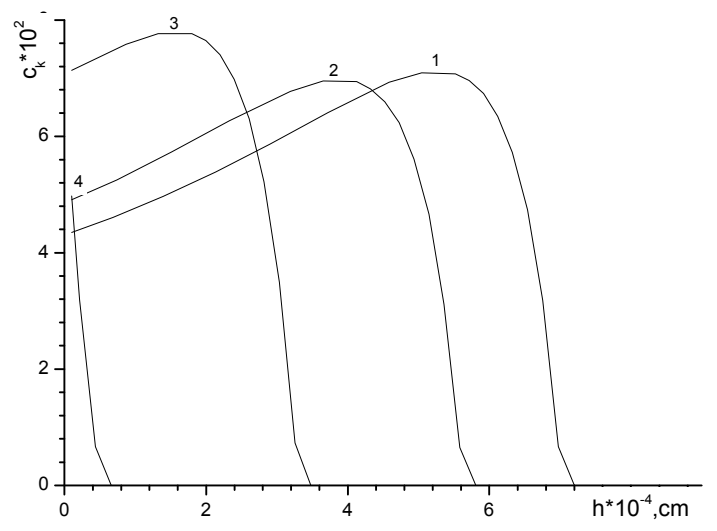

Figure 7 - Sections of allocations on depth of vacancies clusters at an ionic irradiation for nitrogen in iron for $\mathrm{E}_{\mathrm{c}}=100 \mathrm{keV}, \mathrm{E}_{0}=1000$ (1), 800 (2), 500 (3), 200(4) keV.

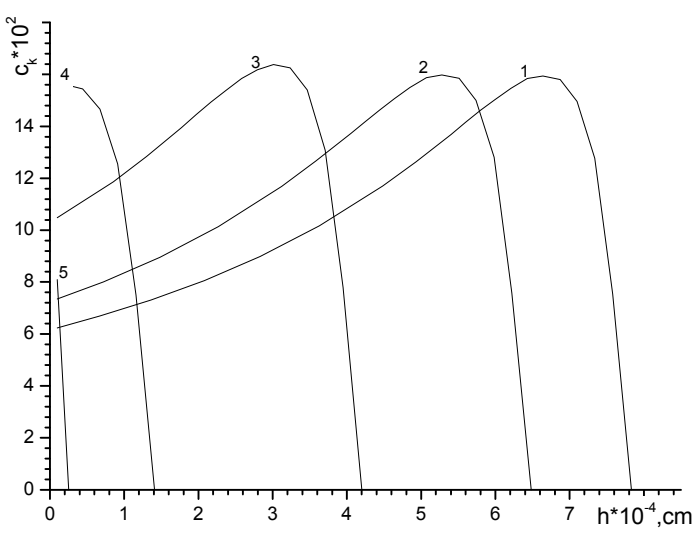

Figure 8 - Sections of allocations on depth of vacancies clusters at an ionic irradiation of iron with carbon ions $(\mathrm{CFe})$ for $\mathrm{E}_{\mathrm{c}}=50 \mathrm{keV}$, $\mathrm{E}_{0}=1000$ (1), 800 (2), 500 (3), 200 (4), 100 (5) keV. 
The regularities of concentration behavior are obtained of radiation defects depending on various factors. For light incident particles and light targets curves are increasing, reaching a maximum and then decrease to zero. At the $E_{c}=50 \mathrm{keV}$ in the sections maximum appears, it shows that localizations of cascade areas occurs on the smallish depth. With increasing atomic weight of the incident particles the value of function at the point of maximum increases and, consequently, curves pass above, while depths values are reduced, that is formed by large concentrations of vacancy clusters in subsurface area. With increasing initial energy of particles the damage area displaces in the depth of the material. At the same $E_{0}$ and $E_{c}$ for heavier particles per unit of ion movement is formed more areas. When the energies of the incident particles is $E_{0}=100 \mathrm{keV}$ the maximum of function on the surface of the target, at that its value small and quickly becomes zero, therefore a very small damaged area is formed that lies within 10-100 nm. Calculations show that when the iron is irradiated with carbon and iron in certain modes (found based on simulation) is hardening of the surface layer in the 1.5-2 times.

\section{Conclusions}

1. Computer simulation of distributions over depth of implanted carbon and iron ions with energies e $=245,350$ and $500 \mathrm{keV}$ and power losses in the iron is done. It is obtained that these curves for the different energies for both carbon and iron in the iron have distinct highs, and their concentration is unevenly distributed in depth. With increasing energy, curves are displaced to the right, and the magnitude of their maxima decreases. Comparison of calculations for carbon $(245 \mathrm{keV})$ and iron (350 $\mathrm{keV}$ ) gives good agreement with experiment.

2. Calculations show that the distribution of energy losses on ionization and excitation on depth of material of carbon and iron in iron is quite sharply decreasing function for all calculated energies $(245,350,500 \mathrm{keV})$.

3. Computer simulation of cascadeprobabilistic functions depending on the depth of penetration in the iron is carried out. As it follows from the calculations obtained, all the dependencies of the CPF lie within a very narrow range of depths and the number of interactions. Depending on $n$ the $\mathrm{CPF}$ with increasing of monitoring depth displace to the right regarding $h / \lambda$, the value of the function at the point of maximum decreases. With increasing atomic weights as the incident particles and target, the behavior of KPF is similar. Depending on the depth of CPF (regarding $h / \lambda$ ) with an increase of the number of interactions is also displaced to the right, the function values at the point of maximum and real areas of finding a result significantly decreases.

4. The analysis of the characteristics of ions depending on the depth of penetration and the number of interactions is carried out. The result is that approximated coefficient of the cross-section (formula 3) is quite good (correlation coefficient more than 0.99) describes a similar amount, calculated using the formula Rutherford and energy losses, shown in tables Kumahova - Komarova. At that the displacement percentage of the left and right borders of the field of CPF result depending on the depth of penetration for ions of iron and carbon in iron $(\mathrm{C} 1, \mathrm{C} 2, \mathrm{C} 3)$ may differ (concerning $\mathrm{h} / \lambda$ ) for $30 \%$.

\section{References}

1.Boos E.G., Kupchyshyn A.I., Kupchyshyn A.A., Shmygalev E.V., Smygaleva T.A., Cascadeprobabilistic method. The solution of radiation physical problems, Boltzmann equations. Association with Markov chains // Abai KazNPU, Al-Farabi Research Institute of new chemical technologies and materials, Kama LLP. - Almaty, 2015. $-388 \mathrm{p}$. 